\title{
Hospital Based Gestational Age Specific Birth Charts in Urban Bangladesh
}

\author{
Dhar $\mathrm{B}^{1}$, Bhadra $\mathrm{SK}^{2}$ \\ ${ }^{1}$ Independent Consultant, Dheskeswari Road, Dhaka, Bangladesh \\ ${ }^{2}$ National Institute of Population Research and Training (NIPORT), Dhaka, Bangladesh \\ e-mail:dharb07@yahoo.com
}

\begin{abstract}
Birth weight is not enough to evaluate growth of the newborn. Around the globe, growth charts at birth as percentiles for various gestational ages are available both in developed and developing countries. This study aimed to develop such growth chart in Bangladesh, to exactly evaluate an individual newborn's growth pattern by comparing growth of its different parts with that of a standard one. A cross sectional observational study conducted at fifteen non-government maternity centers located in different parts of Dhaka, Narayanganj and Narsingdi. Birth weight, birth length, head and chest circumferences of five thousand one hundred and five singleton newborns' with gestational ages ranging from 35 to 42 weeks were recorded during June 2014 to July 2015. Trained Physicians and paramedics of respective centers recorded data. Gestational age specific percentile charts were constructed for birth weight, birth length, head circumference and chest circumference. Mean birth weight, birth length, head and chest circumferences were found to be respectively $2966 \mathrm{~g}, 47.1,33.2$ and $32.3 \mathrm{~cm}$ which were more or less comparable to some other studies in the country and also higher than some of the studies. Most strikingly, prevalence of low birth weight was found to be 11 percent which is significantly lower than any other study conducted in the country. The $10^{\text {th }}, 50^{\text {th }}$ and $90^{\text {th }}$ percentile values of birth weight at $40^{\text {th }}$ weeks of gestation were respectively found to be $2600 \mathrm{~g}, 3000 \mathrm{~g}$ and $3600 \mathrm{~g}$. The linear and circumference growth at $40^{\text {th }}$ weeks of gestation match with the percentile values of birth weight. Constructed growth charts are more or less comparable to some South Asian countries but also significantly differ from some other studies. Country specific standard growth chart is required for clinical assessment and identifying high risk newborns for providing special care. The growth charts constructed in this study, will guide policy makers and programme personnel to take necessary interventions for ensuring potential growth of every future newborn. Furthermore, this study has made the opportunity to compare the charts with other South Asian countries and developed world.
\end{abstract}

Keywords: Birth weight, birth length, head and chest circumference

\section{Introduction}

In Bangladesh, like most other countries, anthropometric studies concerning newborns were primarily focused on birth weight particularly on low birth weight (LBW $<2.5 \mathrm{~kg}$ ). Only individual's birth weight is not sufficient to evaluate the growth of newborns. For example, many of the growth-retarded babies have birth weights either equal to or greater than $2.5 \mathrm{~kg}$. ${ }^{1}$ Again, though preterm babies (gestational age $<37$ completed weeks) usually weigh $<2.5 \mathrm{~kg}$, their growth pattern is different from that of intrauterine growth retarded LBW babies.
Therefore, taking only weight of the babies, whether they have grown normally or not in the uterus, could not always be able to assess appropriately. For proper interpretation of growth, Lubchenco first described anthropo-metry at birth as percentiles for various gestations. ${ }^{2}$ Thereafter, to interpret the growth of newborns at birth developed countries as well as many developing countries have constructed growth charts at birth as percentiles for various gestations. Usually, growth charts are constructed for birth weight, birth length and head circumference. To recognize the individual baby's risk, a useful supplement to other observations during the early 
hours after birth is the recording of the baby's weight, length, and head circumference on the intrauterine growth charts. However, in Bangladesh, so far no such charts have been developed. Therefore, due to absence of such chart, no one can evaluate exactly an individual newborn's growth pattern by comparing growth of its different parts (birth weight, length, head circumference) with that of a standard chart. The position of the infant's measurements on the charts may indicate that $\mathrm{s} / \mathrm{he}$ is within the usual borders of growth for his/her gestational age, s/he may be near or outside of the extremes of normal growth, or there may be inconsistencies between the percentile positions of weight, length, and head circumference.

For liveborn babies, both short and long term consequences of abnormally grown foetus are critical. Newborn and infant mortality and morbidity are significantly high among these babies. ${ }^{3-4}$ Those who survive adulthood are more likely to suffer from chronic diseases like hypertension, coronary heart disease, diabetes mellitus and obstructive lung disease. ${ }^{5}$ To prevent these adverse effects, growth charts can be used at primary health care level to screening the vulnerable babies for proper attention by the appropriate health care providers. The incidence of growth retarded infants is high in the country. ${ }^{6}$ Development of growth charts for different parameters and their use by health care providers obviously will play vital role in identifying the growth retarded newborns. Furthermore, as the study was conducted with reasonably large sample size, with certain limitations, the constructed growth charts can be used as reference or even test charts in the country. Once it is considered the magnitude of the problem of growth retardation, the public health professionals and clinicians will feel encourage to use the growth charts for screening and necessary intervention for newborns at risk. Essential instruction can also be provided to mothers and other care givers for taking proper care to those babies at home.

The objectives of the study were to construct gestational age specific centile charts for weight, length, weight length ratio, head circumference and chest circumference at birth and also to assess the growth of newborn and to compare the constructed charts with similar charts in other countries.

\section{Materials and Methods}

This was a cross-sectional observational study carried out at fifteen non-government maternity centers located in Dhaka North and South City Corporations, Narayanganj, Narsingdi and Keraniganj. Birth weight, birth length, head and chest circumferences of 5,105 singleton newborns with gestational age ranging from 35 to 42 weeks were recorded over a period of 14 months from June 2014 to July 2015.

Trained physicians and paramedics of respective maternity centers recorded the data in the questionnaire which was pretested and modified earlier. The centers included 8 maternity clinics of Urban Primary Health Care Project (UPHCP-2) in Dhaka; five clinics of Marie-Stopes Society (Two centers at Dhaka and three at Narayanganj, Narsingdi and Keraniganj); Ad-din Hospital, Dhaka; and maternity center of Reproductive Health Services Training and Education Program (RHSTEP) Dhaka. These are secondary level maternity clinics in the country, where pregnant women mostly from middle and lower class attend these centers for antenatal care, delivery and postnatal care. The gestational age was calculated in completed weeks either from the date of last menstrual period or from the early dating ultrasound report. Cases with uncertain gestational age were excluded from the study. The weights of newborns were measured on a digital weighing machine with a variability of $50 \mathrm{~g}$. The weighing machines were checked frequently with known standard weight and calibrated during each session. The head and chest circumferences were measured with a fibre-glass measuring (nonstretchable) tape to the nearest of $0.1 \mathrm{~cm}$. Maximum occipito-frontal circumference of head was recorded and chest circumference was measured at the level of nipple at the end phase of expiration. The length of the infant was measured in centimeter on an infantometer with the baby supine, knees fully extended and soles of the feet held firmly against the foot board and head 
touching the fixed board. These centres usually do not deal with any form of risk pregnancy. Thus, it was obtained anthropometric data of newborns of normal pregnancy. A very few number of cases was obtained before 35 weeks of gestation and therefore was not included in the study. Post mature babies (after 42 weeks of gestation) were also excluded.

SPSS software (version 20) was used for data analysis. Percentile tables for weight, length, weight-length ratio, head and chest circumferences and growth curves are presented and comparison is made with other related studies. Percentiles charts were constructed using the LMS Chart Marker Software. ${ }^{7}$ LMS chart maker is a program to fit smooth centile curves to reference data using the LMS method. The LMS method summarizes the changing distribution by three curves representing the skewness $(\mathrm{L})$, median $(\mathrm{M})$ and coefficient of variation (S). Using penalized likelihood the three curves can be fitted as cubic splines by non-linear regression, and the extent of smoothing required can be expressed in terms of smoothing parameters or equivalent degrees of freedom. Percentiles drawn for this study were $10^{\text {th }}, 25^{\text {th }}, 50^{\text {th }}, 75^{\text {th }}$ and $90^{\text {th }}$ to construct the charts.

\section{Results}

Five thousand one hundred and five singleton live birth newborn babies' birth weight, length, head and chest circumference were recorded from fifteen non-government maternity centres. Gestational age of these newborns ranges from 35 to 42 weeks. Centre specific mean anthropometric values did not vary significantly. Mean values for birth weight, length, head and chest circumference were found to be respectively $2966 \mathrm{~g}, 47.1,33.2$ and $32.3 \mathrm{~cm}$. Anthropometric measurements between male and female newborns were also not found to vary significantly (table I).

The number of newborns with birth weight less than $2500 \mathrm{~g}$ was found to be only 11 percent. Percentage of low birth weight $(<2500 \mathrm{~g})$, inadequate birth weight $(2500-<3000 \mathrm{~g})$ and adequate birth weight $(\geq 3000 \mathrm{~g})$ for male newborns were found to be $10.7,40.5$ and 48.8 percent respectively and that for female newborns were $11.2,43.9$ and 44.8 percent respectively, while for both sexes combined values were found to be $11.0,42.1$ and 46.9 percent respectively (table II).

Table I: Mean anthropometric parameters by each sex separately and combined

\begin{tabular}{lllll}
\hline \multicolumn{1}{c}{ Sex } & $\begin{array}{l}\text { Birthweight (g) } \\
\text { Mean (SD) }\end{array}$ & $\begin{array}{l}\text { Length } \\
(\mathbf{c m}) \\
\text { Mean (SD) }\end{array}$ & $\begin{array}{l}\text { HC (cm) } \\
\text { Mean } \\
\text { (SD) }\end{array}$ & $\begin{array}{l}\text { CC (cm) } \\
\text { Mean } \\
\text { (SD) }\end{array}$ \\
\hline $\begin{array}{l}\text { Male } \\
(\mathrm{n}=2683)\end{array}$ & $2987(394)$ & $47.2(1.7)$ & $33.4(1.9)$ & $32.4(1.9)$ \\
$\begin{array}{l}\text { Female } \\
(\mathrm{n}=2422)\end{array}$ & $2944(392)$ & $47.0(1.7)$ & $33.0(2.0)$ & $32.2(1.9)$ \\
$\begin{array}{l}\text { Both sex } \\
(\mathrm{n}=5105)\end{array}$ & $2966(394))$ & $47.1(1.7)$ & $33.2(2.0)$ & $32.3(1.9)$ \\
\hline
\end{tabular}

Table II: Birth weight status of male and female newborns separately and of both sexes combined

\begin{tabular}{llll}
\hline Birth weight & Boys & Girls & Both sex \\
\hline $\begin{array}{l}\text { Low birth } \\
\text { weight }\end{array}$ & $288(10.7 \%)$ & $272(11.2 \%)$ & $560(11.0 \%)$ \\
$\begin{array}{l}\text { Inadequate } \\
\text { birth weight }\end{array}$ & $1087(40.5 \%)$ & $1064(43.9 \%)$ & $2151(42.1 \%)$ \\
$\begin{array}{l}\text { Adequate } \\
\text { birth weight }\end{array}$ & $1308(48.8 \%)$ & $1086(44.8 \%)$ & $2394(46.9 \%)$ \\
\hline
\end{tabular}

Only 4 percent newborns were born prematurely (before 37 weeks of pregnancy).

Percentile distribution of birth weight, length, weight-length ratio, head and chest circumferences (for both sexes combined) are presented in table III and birth charts are constructed for birth weight, length, head and chest circumferences (figure 1-4).
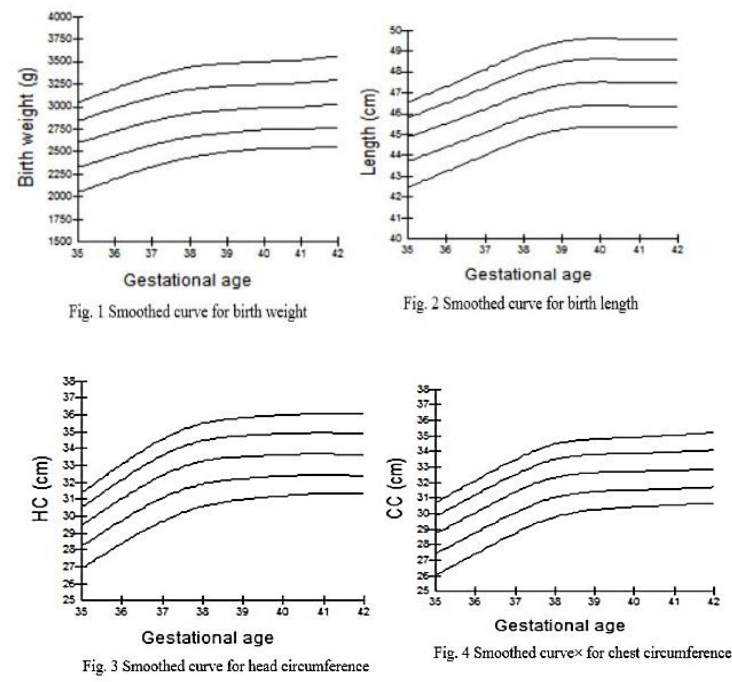

The $10^{\text {th }}, 50^{\text {th }}$ and $90^{\text {th }}$ percentile values of birth weight at $40^{\text {th }}$ week of gestation were found to be $2600 \mathrm{~g}, 3000 \mathrm{~g}$ and 3600g. The linear and 
circumference growth at $40^{\text {th }}$ weeks of gestation match with the percentile values of birth weight.

Table III: Intrauterine growth standard by weight, length, weight - length ratio, head circumference and chest circumference

\begin{tabular}{|c|c|c|c|c|c|c|c|}
\hline \multirow{2}{*}{$\begin{array}{l}\text { Gestational age } \\
\text { (week) }\end{array}$} & \multirow{2}{*}{$\begin{array}{l}\text { No. of } \\
\text { newborn }\end{array}$} & \multirow[t]{2}{*}{ Mean } & \multicolumn{5}{|c|}{ Percentiles both sexes } \\
\hline & & & 10th & 25 th & 50th & 75th & 90th \\
\hline \multicolumn{8}{|l|}{ Weight in gram } \\
\hline 35 & 81 & 2534 & 1920 & 2275 & 2500 & 2875 & 3090 \\
\hline 36 & 120 & 2718 & 2250 & 2450 & 2650 & 3000 & 3250 \\
\hline 37 & 344 & 2832 & 2350 & 2550 & 2860 & 3050 & 3300 \\
\hline 38 & 729 & 2944 & 2450 & 2665 & 2960 & 3200 & 3480 \\
\hline 39 & 950 & 2964 & 2450 & 2700 & 2950 & 3250 & 3520 \\
\hline 40 & 1797 & 3010 & 2600 & 2780 & 3000 & 3260 & 3600 \\
\hline 41 & 818 & 3002 & 2500 & 2750 & 3000 & 3200 & 3550 \\
\hline 42 & 266 & 3061 & 2550 & 2800 & 3000 & 3337 & 3650 \\
\hline \multicolumn{8}{|l|}{ Length in $\mathrm{cm}$} \\
\hline 35 & 81 & 44.5 & 42.1 & 43.4 & 44.6 & 46.1 & 46.6 \\
\hline 36 & 120 & 45.4 & 43.4 & 44.5 & 45.6 & 46.5 & 47.0 \\
\hline 37 & 344 & 45.9 & 44.1 & 45.0 & 46.0 & 46.8 & 47.8 \\
\hline 38 & 729 & 46.8 & 44.8 & 46.0 & 46.8 & 47.7 & 48.6 \\
\hline 39 & 950 & 47.3 & 45.2 & 46.4 & 47.2 & 48.0 & 49.0 \\
\hline 40 & 1797 & 47.5 & 45.8 & 46.8 & 47.6 & 48.3 & 49.3 \\
\hline 41 & 818 & 47.4 & 45.4 & 46.5 & 47.3 & 48.0 & 49.2 \\
\hline 42 & 266 & 47.5 & 46.0 & 46.7 & 47.4 & 48.0 & 49.2 \\
\hline \multicolumn{8}{|c|}{ Weight length ratio $(100 \times$ weight in gm/length cube in $\mathrm{cm})$} \\
\hline 35 & 81 & 2.86 & 2.4 & 2.6 & 2.7 & 3.0 & 3.4 \\
\hline 36 & 120 & 2.90 & 2.5 & 2.6 & 2.8 & 3.0 & 3.4 \\
\hline 37 & 344 & 2.92 & 2.6 & 2.7 & 2.9 & 3.0 & 3.3 \\
\hline 38 & 729 & 2.86 & 2.5 & 2.7 & 2.8 & 3.0 & 3.2 \\
\hline 39 & 950 & 2.79 & 2.4 & 2.6 & 2.8 & 2.9 & 3.1 \\
\hline 40 & 1798 & 2.81 & 2.4 & 2.6 & 2.8 & 2.9 & 3.0 \\
\hline 41 & 818 & 2.83 & 2.4 & 2.6 & 2.8 & 3.0 & 3.1 \\
\hline 42 & 266 & 2.86 & 2.5 & 2.7 & 2.9 & 3.0 & 3.1 \\
\hline \multicolumn{8}{|c|}{ Head circumference in $\mathrm{cm}$} \\
\hline 35 & 81 & 29.2 & 27.3 & 28.0 & 29.2 & 30.1 & 32.0 \\
\hline 36 & 120 & 30.7 & 28.0 & 29.6 & 30.5 & 32.3 & 32.8 \\
\hline 37 & 344 & 32.3 & 29.6 & 31.0 & 33.0 & 33.8 & 34.5 \\
\hline 38 & 729 & 33.1 & 30.0 & 31.8 & 33.2 & 34.0 & 35.0 \\
\hline 39 & 950 & 33.4 & 30.6 & 32.2 & 33.5 & 34.4 & 35.5 \\
\hline 40 & 1797 & 33.6 & 31.0 & 32.5 & 33.7 & 34.6 & 36.3 \\
\hline 41 & 818 & 33.7 & 31.2 & 32.6 & 33.8 & 34.7 & 36.3 \\
\hline 42 & 266 & 33.5 & 31.0 & 32.3 & 33.7 & 34.7 & 36.3 \\
\hline \multicolumn{8}{|c|}{ Chest circumference in $\mathrm{cm}$} \\
\hline 35 & 81 & 28.5 & 26.0 & 27.3 & 28.2 & 29.8 & 31.0 \\
\hline 36 & 120 & 29.5 & 26.6 & 28.0 & 29.4 & 30.7 & 32.0 \\
\hline 37 & 344 & 31.2 & 28.5 & 29.6 & 31.9 & 32.4 & 33.2 \\
\hline 38 & 729 & 32.3 & 30.0 & 31.5 & 32.6 & 33.4 & 34.2 \\
\hline 39 & 950 & 32.5 & 30.4 & 31.7 & 32.7 & 33.6 & 34.5 \\
\hline 40 & 1797 & 32.6 & 30.8 & 31.8 & 32.9 & 33.7 & 34.8 \\
\hline 41 & 818 & 32.7 & 30.6 & 31.9 & 32.8 & 33.8 & 35.0 \\
\hline 42 & 266 & 32.9 & 30.8 & 32.0 & 32.9 & 34.0 & 35.3 \\
\hline
\end{tabular}

\section{Discussion}

The study presents the sex specific as well as combined mean values of birth weight, length, head and chest circumferences. Incidence of low, inadequate and adequate birth weights were also presented in the study. According to objective, intrauterine growth centiles are presented and smooth curves are constructed for birth weight, length, head and chest circumference.

In Bangladesh, from different birth weight studies, it is observed that mean values differ from study to study. National Low Birth Weight Survey conducted in 2003-04 revealed mean birth weight as 2632g. ${ }^{8}$ Other five small-scale surveys and studies conducted at different time and place shows that mean birth weight varies 
significantly from study to study, ranging from $2420 \mathrm{~g}$ in a rural area to $2889 \mathrm{~g}$ in an urban government maternal hospital. ${ }^{9-13}$ The prevalence of low birth weight in the present study was found to be 11.0 percent which is significantly below in comparison to other studies conducted in the country. In National Low Birth Weight Survey conducted twelve years back found proportion of low birth weight as 36 percent. Whereas the lead author of the present study, in his two previous hospital based studies found prevalence of low birth weight as 15.0 percent and 17.3 percent. ${ }^{6,13}$ Proper antenatal care from the early period of pregnancy of mothers of the newborns, increase of health consciousness of family members and also gradual progression of socioeconomic status of general people might be the reasons for low incidence of low birth weight of the present study.

Though skeletal growth (birth length and head circumference) in intrauterine life is an important determinant for future morbidity and mortality, such records are not documented in most of the studies in the country. National Low Birth Weight Survey recorded birth length and the mean value was found to be $48.5 \mathrm{~cm}$ which does not coincide with the mean birth weight $(2632 \mathrm{~g}){ }^{8}$

Two other studies in the country documented birth length, head circumference and chest circumference and the respective values were found to be $47.9 \mathrm{~cm}, 33.5 \mathrm{~cm}$ and $31.7 \mathrm{~cm}$ for one study, and $48 \mathrm{~cm}, 33 \mathrm{~cm}$ and $31.6 \mathrm{~cm}$ for the other study. ${ }^{6,13}$

Mean anthropometric values of all the variables of the present study do not differ significantly between male and female babies. Therefore, only combine (male and female together) curves have been constructed. As such growth charts with percentile distribution are not available in the country, comparison cannot be shown in country context. However, such charts are available in developed countries as well as in some developing countries including India. The charts can be considered as normative, because women with any known morbidity (e.g. pre-eclampsia/ eclampsia, diabetes mellitus, hypertension) that might interfere with growth were excluded from the study.

In this study, birth weight data at gestational age of $40^{\text {th }}$ week the $10^{\text {th }}, 50^{\text {th }}$ and $90^{\text {th }}$ percentile values were found to be $2600 \mathrm{~g}, 3000 \mathrm{~g}$ and $3600 \mathrm{~g}$ respectively which are lower in comparison to Lubchenco's study. ${ }^{2}$ In a Sri Lankan study corresponding values at $10^{\text {th }}, 50^{\text {th }}$ and $90^{\text {th }}$ were found to be $2580 \mathrm{~g}, 3037 \mathrm{~g}$ and $3600 \mathrm{~g}$ for male babies and 2800g, 3180g and 3600g for female babies. ${ }^{14}$ The results of a Nepalese study are comparable to this study findings. ${ }^{15}$ In one South Indian study corresponding values were found to be lower. ${ }^{16}$

The $50^{\text {th }}$ and $90^{\text {th }}$ percentile values for length of the present study at $40^{\text {th }}$ week of gestation were also found to be lower than Lubchencho's another study, ${ }^{17}$ but $10^{\text {th }}$ percentile value was found to be same $(45.8 \mathrm{~cm})$. Average length at $40^{\text {th }}$ weeks was found to be $47.5 \mathrm{~cm}$ in our study and 49.4 in Lubchenco's study. ${ }^{17}$ However, head circumference values at $40^{\text {th }}$ weeks of gestation were found to be more or less comparable.

The weight-length ratio (ponderal index) reveals how heavy the baby is for its length. Though both birth weight and length were found to be less than that of Lubchenco's studies, deficit of linear growth is more pronounced in this study and therefore weight-length ratio values were found to be more in this study. ${ }^{2,17}$

In different studies, the usual cut off points for intrauterine growth retardation for each gestational age have included $3^{\text {rd }}$ and $5^{\text {th }}$ percentile of birth weight and 2SD below the mean and the more commonly used 10th percentile. ${ }^{18-21}$ However, there are substantial differences in the various published standards that are defined by the $10^{\text {th }}$ percentile alone. For example, in Lubchenco's study, $10^{\text {th }}$ percentile values for birth weight at $40^{\text {th }}$ weeks of gestation was found to be $2630 \mathrm{~g} .{ }^{2}$ whereas in Blinder's study the corresponding value was found to be 2895g. ${ }^{22}$ New Dutch reference curves for birth weight has been constructed for male and female infants born from primiparous and multiparous women and a separate reference curve for Hindustani babies. ${ }^{23}$ Percentile values for Dutch male and female infants at all gestational ages were found to be significantly higher than that of percentile values of this study. Even reference curves for Hindustani babies were found to be higher $(2740 \mathrm{~g}, 3238 \mathrm{~g}$ and $3817 \mathrm{~g}$ respectively for 
$10^{\text {th }}, 50^{\text {th }}$ and $90^{\text {th }}$ percentils at $40^{\text {th }}$ week of gestation) than the values in this study. In one Southern Indian study $10^{\text {th }}$ percentile values at $40^{\text {th }}$ week of gestation for birth weight for males and females were found to be respectively $2488 \mathrm{~g}$ and $2412 \mathrm{~g} .{ }^{16}$ In another Southern Indian study at same gestational age, $10^{\text {th }}$ percentile values for birth weight for males and females were found to be respectively $2850 \mathrm{~g}$ and $27660 \mathrm{~g}$, and 50th and $90^{\text {th }}$ percentile values were found to be $3258 \mathrm{~g}$ and $3764 \mathrm{~g}$ for male babies and that for females babies were $3155 \mathrm{~g}$ and $3652 \mathrm{~g}$ respectively. In the same study, mean length at $40^{\text {th }}$ week of gestation were found to be respectively $50.3 \mathrm{~cm}$ and $49.8 \mathrm{~cm}$ for male and female babies and mean head circumference values at $40^{\text {th }}$ week was found to be $34.3 \mathrm{~cm}$ and $33.9 \mathrm{~cm}$ respectively. ${ }^{24}$ Accordingly, it is clearly revealed that anthropometric values of newborns at birth differ from study to study and also from population to population. Therefore, country specific and even area specific birth charts are necessary.

In spite of the best effort in calculating the percentiles using considerably large cohort, the study has yet certain limitations. There were fifteen centers from where data were collected and inter-center variability in anthropometric measurements is not unlikely. Even in the same center anthropometric measurements were under taken by different doctors or paramedics which might have contributed to inter-observer variability. Moreover, many women might not accurately remember the date of last menstrual period. Furthermore, data were collected from all socioeconomic groups and hence might not reflect the ideal potential for intrauterine growth. However, it is needless to say that, this is an important step in developing growth charts at birth for the first time in the country.

\section{Conclusion}

Growth chart at birth for weight, length and head circumference is prerequisite to help in clinical assessment and identifying high risk newborns for special care. The constructed growth charts will also guide policy makers and programme managers to undertake necessary strategies and interventions for ensuring potential growth of every future newborn. The study also creates an opportunity to comparing these charts with that of other South Asian countries as well as developed world. Growth charts should be periodically reviewed to examine the temporal influence of socioeconomic and socio demographic changes on growth of newborns. It should be updated at least in every five year interval. Furthermore, construction of population based growth chart for nationwide use in the country is also recommended.

Acknowledgments: Authors would like to acknowledge deeply the mothers of newborns who allowed us to undertake anthropometric measurements of their newborn babies. Authority of fifteen maternity centres deserves appreciation for letting us in conducting the study. Doctors and paramedics of the respective maternity centres also deserve special thanks for their inexorable effort in collecting data. Finally, we are profoundly grateful to BMRC for necessary funding to completing the study.

\section{References}

1. Rosso P. Morbidity and Mortality in Intrauterine Growth Retardation. In: Intrauterine growth Retardation, edited by Jacques Senterre. Nestle Nutrition Workshop. 1989; 18: 123-42.

2. Lubchenco LO, Hansman C, Dressler M, Boyd E. Intrauterine growth as estimated from live born birth weight data at 24-42 weeks of gestation. Pediatrics. 1963; 32: 793-800.

3. Starfield B, Shapiro S, McCormik M, Bross D. Mortality and morbidity in infants with intrauterine growth retardation. J Pediatr. 1982; 101: 978-83.

4. Low J A, Galbraith RS, Muri D, Kellen H, Karchmar J, Campbell D. Intrauterine growth retardation. A preliminary report of long-term morbidity. Am J Obstet. Gynecol. 1978; 130: 53445.

5. Barker DJP. The foetal origins of diseases of old age. Eur J Clin Nutr. 1992; 46(suppl.3): S3-S9.

6. Dhar B. Determinants of Intrauterine Growth Retardation (IUGR). Ph.D dissertation-2008; University of Dhaka.

7. Cole TJ. Fitting smoothed centile curves to reference data. J R Stat Soc. 1988; 151:385-418.

8. National Low Birth Weight Survey of Bangladesh (2003-04). Bangladesh Bureau of Statistics, E-27/A Agargaon, Sher-e-bangla Nagar, Dhaka, 2005.

9. Goodburn E, Chowdhury M, Gazi R. Low birth weight in Rural Bangladesh. J. Trop.Pediatr.1994; 40:123 
10. Shaheen R, Arifeen SE, de Francisco A. The optimal duration of nutrition supplementation for malnourished pregnant women. In: Findings of studies performed under the BINP Operations Research Project (ORP). 2000; Vol 2., eds. Osendarp SMJ, Roy SK, Fuchs GJ. Dhaka: ICDDR'B, Dhaka. B 8-9.

11. Arifeen SE, Black RE, Caulfield LE, Antelman G, Baqui AH, Nahar Q et. al. . Infant growth patterns in the slums of Dhaka in relation to birth weight, intrauterine growth retardation, and prematurity. Am J Nutr. 2000; 72: 1010-17.

12. Canosa CA. Intrauterine growth retardation in India and Bangladesh. In: Sentre J, ed. Intrauterine growth retardation. Nestle Nutrition Workshop series. 1989; 18: 183-204.

13. Dhar B, Mowlah G, Nahar S, Islam N. Birth weight status of newborns and its relationship with other anthropometric parameters in a public maternity hospital in Dhaka, Bangladesh. J Health Popul Nutr. 2002; 20:36-41.

14. Ruwanparthirana T, Fernando Dulitha $\mathrm{N}$ and Senanayake Hemanta. Development of birth weight for gestational age charts in a Sri Lanka settingmethodological issues. WHO South-East Asia Journal of Public Health. 2013; 2: 47-51.

15. Aryal DR, Gurung R, Misra S, Khanal P, Pradhan A, Gurubacharya. Intrauterine Growth Curves for Singleton Live Babies in Paropakar Maternity and Women's Hospital in Nepal. J Nepal Health Res Counc. 2012;10:160-66.

16. Alexander A.M, George K, Muliyil J, Bose A, Prasad J. Birth weight centile charts from community-based Data from South India. Indian pediatrics. 2013;50:1020-24
17. Lubchenco LO, Hansman C, Boyd E. Intrauterine growth in length and head circumference as estimated from live born births at gestational ages from 26-42 weeks of gestation. Pediatrics. 1966; 37 : 403-08.

18. Fancourt R, Campbell S, Harvey, Norman AP. Follow-up- study of small-for-dates babies. $\mathrm{Br}$ Med J. 1976; 1:1435-37.

19. Villar J, Belizan, JM, Spalding J, Klein RE. Postnatal growth of intra uterine growth retarded infants. Early Hum Dev. 1982; 6: 265-71.

20. Villar, J, Belizan, JM. The evaluation of the methods used in the diagnosis of intrauterine growth retardation. Obstetrical and Gynaecological Survey. 41: 187-99.

21. Richard G. Pearse. Definitions: Problems and Limitations of Intrauterne Growth curves. In: Intrauterine growth Retardation, edited by Jacques Senterre. Nestle Nutrition Workshop 1989; 18: 65-77.

22. Blidner IN, McClemont S, Anderson GD, Sinclair JC. Size-at-birth standards for an urban Canadian population. Can Med Assoc J. 1984; 130: 133-40.

23. Gerard HA, Visser, Paul H C, Eliers, Patty M, Elferink-Stinkens et al. New Dutch reference curves for birthweight by gestational age. J. Early Human Development. 2009; 85:737-44.

24. Kandraju H, Agrawal S, Geetha K, Sujatha L, Subramanian S and Murki S. Gestational agespecific centile charts for anthropometry at birth for South Indian Infants. Indian Pediatrics. 2012; 49:199-202. 